\title{
Afecto, efecto y realismo en las tres últimas novelas de Ruffato
}

\author{
Affect, Effect and Realism in Ruffato's Latest Novels \\ Afecto, efecto y realismo en las tres últimas novelas de Ruffato
}

Matias Rebolledo Dujisin

\section{Resumen}

Es bien sabido que la poética escritural de Luiz Ruffato consiste en la recuperación del proyecto realista, de su compromiso político y social y de la búsqueda formal de estrategias escriturales que comuniquen la experiencia de su tiempo. Su novela eles eram muitos cavalos es paradigmática de las transformaciones estéticas que buscan responder a las nuevas condiciones de realidad. Sin embargo, en sus últimos textos el autor pareciera dar un vuelco a la experimentación formal que caracterizaba a los textos que le dieron renombre. En las tres novelas analizadas en este artículo el autor asegura transcribir relatos de individuos reales, donde solo participaría como editor; de este modo se aleja del relato fragmentario que explora la potencia significante del lenguaje y construye una narración simple y oralizada. La propuesta de este artículo es enmarcar estos textos dentro de la problemática de los realismos actuales, discutiendo su lugar dentro del proyecto ruffatiano, y planteando como hipótesis el lugar central del esfuerzo de reconstitución de un sujeto fragmentado e inalcanzable, como gesto estético y político en estas novelas.

Palabras-clave: realismo, ficción y realidad, sujeto, Luiz Ruffato.

\section{Abstract}

It's known that Luiz Ruffato's purpose in his writing is the renewal of the classical realist project, including its political and social undertaking and formal experimentation that resonates with the experience of reality. They Were Many Horses is by now a critical model of the aesthetic explorations that reflect on the new conditions of contemporary reality. However, in his lastest words the author seems to have shifted away from the formal experimentation that distinguishes his most famous texts. In his latest three novels, the author claims only to transcribe, as an editor, the speech of real individuals. In so doing, he is he takes a step back from his fragmentary narratives that explore the the significance of language, to elaborate simple and oral-like narratives. The aim of this article is to frame these novels within questions of "new" realisms, discussing how they participate in the author's project, and postulating that the reconstruction of a fragmented and ultimately unattainable subject is the main politic and aesthetic proposition of these novels.

Keywords: realism, fiction and reality, subject, Luiz Ruffato.

\section{Resumo}

A poética escritural de Luiz Ruffato, é sabido, consiste na recuperação do projeto realista, do seu compromisso político e social, e da experimentação formal de estratégias da escrita que ecoem a experiência de realidade. Seu romance eles eram muitos cavalos resulta hoje paradigmático destas mutações estéticas que procuram dar resposta às novas condições de realidade. No entanto, nos seus últimos textos o escritor parece ter dado um giro na experimentação formal que distinguia os textos que deram-lhe renome. Nos três romances analisados neste artigo o autor assegura simplesmente transcrever relatos de indivíduos reais, participando unicamente como editor; assim, se afasta da narrativa fragmentaria que explora a força significante da linguagem e constrói um relato simples e oralizado. A proposta deste artigo é enquadrar estas narrativas dentro da problemática dos realismos atuais, problematizando o seu lugar dentro do projeto ruffatiano e propondo a hipótese do lugar central que tem a reconstituição do sujeito fragmentado e intangível como gesto estético e político nestes romances.

Palavras-chave: realismo, ficção e realidade, sujeito, Luiz Ruffato.

\footnotetext{
*Universidad de Chile, Santiago, Chile. Dorcid.org/0000-0002-6433-7417. E-mail: majorebo@u.uchile.cl
} 


\section{La poética/política escritural de Ruffato y el realismo como problema}

Aunque su primera novela apareciera hace solo dieciocho años, mucha tinta ha corrido ya en torno a la obra del minero Luiz Ruffato, cuyo proyecto literario ocupa un lugar preponderante en el modelamiento escritural de los realismos contemporáneos. Empieza a publicar libros de cuentos a finales de los noventa, con una propuesta escritural bien definida: la recuperación de la tradición realista, de su compromiso político y social, y su capacidad de intervenir en la sociedad, pero desarrollando estructuras y técnicas narrativas que respondan a las condiciones materiales y experienciales del individuo contemporáneo. Dicha po-ética escritural sirve como matriz a la gran diversidad estilística y temática de su obra, y supone aún un largo proceso de búsqueda/aprendizaje; sus primeros libros de cuentos, Histórias de remorsos e rancores (1998) y (os sobreviventes), de 2000, serían luego revisados y refundidos en la pentalogía de Inferno Provisório, nunca reeditados, entendiéndolos como meros antecedentes. Los temas y formas de la novela han de revitalizarse, rompiendo con un paradigma que nunca se propuso como definitivo y que evidentemente se ha anquilosado, si aún queremos suponer una validez crítica y estética del realismo.

Ruffato, es bien sabido, no está solo en esta empresa. Las condiciones políticas y sociales del capitalismo avanzado y sus efectos en nuestro continente, la globalización y las nuevas tecnologías son la base para una búsqueda sobre las posibles construcciones de realidad basadas en la experiencia concreta, en un distingo consciente con el realismo decimonónico, pero, digamos, manteniendo su espíritu (tal como el realismo clásico fue la respuesta estética al capitalismo industrial y la moral burguesa). De este modo, se comprende que la divergencia formal, temática y estilística de la novela brasileña actual es la marca más precisa (y preciosa) de estas propuestas. Situado en este panorama de renovación de las formas literarias en Brasil, su primera novela, eles eram muitos cavalos (2001), parece condensar significativamente el proceso innovador de estas narrativas. Su repercusión crítica permitió, a su vez, que el autor formulara claramente su proyecto:

A forma clássica do romance foi adequada para resolver problemas do início da Revolução Industrial. Depois, ela foi tendo que se adaptar aos novos tempos, até chegar a Joyce. $\mathrm{O}$ instrumento romance, com começo-meio-fim, não faz sentido diante da quantidade de informações de hoje, ficou obsoleto. Minha opção pelo fragmentário foi tuna provocação mesmo. Quando eu publiquei o eles eram muitos cavalos, muitos críticos torceram o nariz e disseram "mas isto não e um romance". Também acho que não é. Mas o que é? Não é um livro de contos. Quero colocar em xeque essas estruturas. Não quero fazer uma reflexão só sobre a realidade política, mas também questionar por meio do conteúdo a forma ("Entrevista").

Si la literatura es capaz de representar la realidad es también capaz, dentro de sus propios límites, de producir cambios en ella. Pero la novela no puede seguir dependiendo de un modelo centenario que ha mucho tiempo se ha divorciado de sus fines originales.

Consecuentemente, este problema de los 'nuevos realismos' ha ocupado un lugar significativo en la crítica (brasileña y argentina principalmente) de estas últimas décadas. ${ }^{1}$ Debo aclarar que el etiquetado de 'nuevos' no me parece el más feliz: la carga semántica que se vuelca sobre la 'novedad' nos ha hecho desviar la atención hacia una radicalmente repetitiva innovación, que no tiene nada de nueva. He ahí, también, la razón de la abundancia de adjetivos y nombres para intentar caracterizar un movimiento bastante heterogéneo, aun cuando persigan fines similares. ${ }^{2}$ Dicha proliferación solo me parece significativa por la compulsión a nominar fenómenos como una especie de acto de apropiación (teórica, en este

\footnotetext{
${ }^{1}$ Ver, por ejemplo, entre muchas otras, la compilación Novos realismos (Margato y Cordeiro, 2012); el volumen 39 de la Revista Estudos de Literatura Brasileira Contemporânea; las diversas publicaciones de K. E. Schøllhammer (2009, 2012a, 2012b, 2016); en Argentina, el volumen 12 (2005) del Boletin del Centro de Estudios de Teoría y Crítica Literaria de la U. de Rosario (con publicaciones de Martín Kohan, Sergio Delgado, Graciela Speranza, entre otros), y un largo etcétera.

${ }^{2}$ Son muchos los "tipos" de realismo, pero me parecen los más relevantes el "realismo indicial" y el "realismo afectivo", planteado por Schøllhammer; el "realismo idiota" de Speranza; el realismo "inverosímil" y "ostensivo", de Luz Horne; "realismo brutal", de Cordeiro, etc. El listado podría ser bastante más largo, pero baste como ejemplo.
} 
caso), especial pero no exclusivamente a partir de los prefijos neo-, post-, o similares. Dicha compulsión, lo repito, me parece innecesaria, poco productiva y altamente caduca, aunque los términos en que se definen dichos conceptos me parecen un lugar de partida indispensable para la discusión y la reflexión.

Creo, más bien, que este regreso forma parte de la evolución dialéctica propia del realismo. La realidad cambia (digamos, las percepciones y configuraciones de realidad son por esencia mutables) y junto con ella deben cambiar las técnicas, estrategias y tecnologías de la representación; la literatura cambia, y por ende cambian los estilos, las convenciones y los recursos de la literatura de avanzada. De este modo, me parece mucho más interesante no enfocarnos en la novedad de estas distintas propuestas, sino en cómo se conectan éstas con algunos principios generales de las búsquedas realistas (remarcando con esto la característica inherentemente asintótica de este proceso, sus variantes y su progresión), pero a su vez rompiendo conscientemente con los modelos heredados del realismo decimonónico. Y esto no por un simple afán innovador, como sugiere esta idea de 'nuevos' realismos, sino precisamente por la consciencia de que la experiencia social del capitalismo burgués del XIX se parece muy poco a la experiencia de mundo del capitalismo financiero y globalizado del XXI. El problema, pues, no está en la obsolescencia del realismo clásico, sino en cómo se fue naturalizando y por ende anquilosando como forma, perdiendo su relación naturalmente dialéctica con la realidad. ${ }^{3}$ En las narrativas actuales, la pregunta se sostiene: ¿cómo dar cuenta literariamente -de manera convencional, con las limitaciones del lenguaje como sistema semiótico- de la experiencia fragmentada, virtualizada, globalizada, superficial (etc.), de la (post)modernidad del XXI? Como posible respuesta al nihilismo postmoderno, se instala una generación de autores que ha comenzado a repensar el realismo y las posibilidades de representación literaria, proponiendo así nuevas formas de comprender y por ende de intervenir en la realidad, asumiendo las contradicciones y limitaciones que el postmodernismo develó, y que no solo incorporan, sino que utilizan como herramienta/arma.

De este modo, la 'novedad' de los nuevos realismos estriba más bien en una recuperación de determinados objetivos de la novela clásica, en una sociedad para la cual dicho modelo ya no supone una respuesta, como lo indicaba Ruffato en su entrevista. El 'borramiento' teórico del realismo a la luz de la crítica postestructural, resulta a la distancia demasiado simplificador, ${ }^{4}$ pero es precisamente a partir de este silenciamiento crítico que aparece la necesidad de repensar los realismos, conectando las dimensiones más experimentales de la literatura con lo político y lo social. El neoliberalismo y la globalización, la virtualización de la realidad, y claramente las nuevas tecnologías han creado nuevas percepciones de las estructuras y prácticas políticas y sociales, nuevas formas de sociedad, de marginalidad, de organización de los afectos, visibilizando diversas dimensiones de experiencia. Y debemos recordar que en su tiempo el realismo fue la literatura polémica y rupturista, tanto por las temáticas (la democratización de los objetos de representación), como por las mismas técnicas narrativas que crearon o perfeccionaron para lograr sus objetivos. Así que lo que se suele ver como la forma 'clásica' de la novela, a veces con un sentido peyorativo, fue en su momento provocador. Es la crítica la que se vuelve conservadora.

Sin embargo, hay que considerar que pocas palabras han sido más (ab)usadas, trastocadas, glorificadas y desacreditadas como la de realismo en literatura. Desde que fuera acuñado hace más de siglo y medio, ha pasado a significar cosas tan diversas, que toda especificidad del término pareciera esfumarse. En este sentido, es necesario aclarar algunas de las características definitorias del concepto tal como es entendido en este trabajo, que nos permitirán conectar su

\footnotetext{
${ }^{3}$ Como propone Robbe-Grillet en "Del realismo a la realidad" (en Por una nueva novela, 1965, p. 181-191), donde señala que este proceso de renovación del realismo le es connatural, puesto que cualquier forma al normalizarse se agota, pero sobre todo porque al cambiar el mundo deben cambiar las estrategias para representarlo, y toda nueva forma de representación contribuye, a su vez, a crear nuevas formas de ver la realidad.

${ }^{4}$ Pam Morris (2003, p. 7-44) dedica un par de capítulos muy didácticos a las críticas tanto desde la Vanguardia y la Escuela de Frankfurt como desde el postmodernismo y posestructuralismo al realismo. La crítica al pensamiento ilustrado en general, a todos los metarrelatos ideológicos; el sistema cerrado de signos que componen el lenguaje y la imposibilidad de llegar a un conocimiento racional que lo sobrepase, estarían en la base ideológica de esta crítica. Así, al arte realista se le atribuye la generación de conocimiento ilusorio y, como señala Lyotard, desde un conservadurismo estético e ideológico, que aspira a un (re)conocimiento de mundo en base a certezas morales, totalidad, coherencia.
} 
tradición clásica con los nuevos modos de representación con que experimenta Ruffato. No es posible establecer un único modelo formal de novela realista ni un propósito único, a riesgo de fijar un paradigma histórico sin solución de continuidad con el presente, lo que dista mucho del propósito del realismo.

Desde las propuestas de sus principales teóricos, así como de las diversas características formales y estilísticas de los textos, se establece una presuposición básica, que es que independientemente del estilo o la forma, independientemente de las limitaciones ontológicas del lenguaje mismo, es posible representar o entregar un acercamiento cognitivo a la realidad material, histórica, en al menos algunas de sus dimensiones. ${ }^{5}$ Esto, además, con plena conciencia de la artificiosidad del lenguaje y sus posibles configuraciones: los escritores realistas nunca consideraron de manera tan trivial la relación realidad / texto como sus críticos han planteado. ${ }^{6}$ El realismo literario parte de la base de que es posible comunicar una realidad posible ('imitar' $\sin$ un original previo) ${ }^{7}$ a través del lenguaje. Esa es la presuposición básica, y no la de confundir literatura con verdad, lenguaje con realidad. ${ }^{8}$ La posibilidad de representación supone la construcción de un modelo -literario: ficcional, convencional, estético- comunicable, cuya estructura debe asimilarse no a la verdad a secas, sino a los modelos cognitivos de realidad del lector esperado. Lo que, nuevamente, nos instala en la transitoriedad de los modelos realistas, puesto que responden también a las expectativas lectoras, que son históricas y sociales. ${ }^{9}$

Secundando a estas premisas básicas, la práctica del realismo se asocia a un compromiso político o social, un punto de partida ético en relación con aquello que representa. Es un compromiso de representar lo real histórico en alguna de sus dimensiones, de un modo que pretenda un grado de verosimilitud. Personajes e historias enraizados en su estructura social, su situación histórica, pero también suficientemente individualizados. ${ }^{10}$ La renovación (o puesta en crisis) del personaje actual, como se ve en las novelas aquí tratadas, van de la mano con la difuminación de las estructuras sociales 'tradicionales', y con la caída del 'sujeto solar' (Costa Lima) moderno.

Las renovaciones formales de los realismos actuales, pues, siguen este camino. Tal vez me quede por decir que dichas estrategias apuntan a una lectura 'intencionadamente' realista en el receptor; esto es, que provoque la construcción imaginaria de una realidad posible, que gracias a la asociación experiencial con su propia realidad (su entorno cognitivo), genere, a partir de la lectura, miradas críticas sobre lo real concreto. De esta manera, el realismo es tanto una respuesta a las condiciones materiales como una propuesta interpretativa y crítica de dicha realidad, a la vez que una respuesta a la práctica literaria de su presente (restricciones,

\footnotetext{
${ }^{5}$ Para Lukács, "el verdadero gran realismo retrata al hombre total y a la sociedad total, en cambio de limitarse a algunos de sus aspectos", y señala que "la categoría central, el criterio fundamental de la concepción literaria realista es el tipo, o sea, la particular síntesis que, tanto en el campo de los caracteres como en el de las situaciones, une orgánicamente lo genérico y lo individual [, donde] confluyen y se funden todos los momentos determinantes, humana y socialmente esenciales, de un periodo histórico" (1965, p. 13). Para Auerbach (2001), el realismo es un modo histórico de representación que se va adecuando a las condiciones históricas de su producción, y supone un progresivo rompimiento de la separación entre 'alta' y 'baja' literatura, democratizando la representación literaria; lo 'real', por otra parte, se identifica con lo histórico en su reflexión. Para Brecht, el parámetro del realismo es la realidad misma, y las condiciones formales de la literatura se deben adecuar a sus propósitos.

${ }^{6}$ Lyotard, por ejemplo, uno de sus enemigos declarados, propone casi al pasar que su única definición de realismo es "que se propone evitar la cuestión de la realidad implicada en el arte", y que "se encuentra siempre en una posición situada entre el academicismo y el kitsch" (1987, p. 16-17).

${ }^{7}$ Cfr. Costa Lima (2000, p. 22): “O que [...] é fundamental no fenômeno da mímesis é a correspondencia estabelecida entre uma obra particular - a cena segunda- e parâmetros que guiam o receptor" (es decir, no existe la escena "original" de la que segunda sería una "copia", sino parámetros culturales que funcionan como "balizas" interpretativas).

8 "No writer attempting to reach beyond words can fail to be struck by the work words do and cannot do, and therefore no such writer can fail to recognize the degree to which the creation of illusion is essential to the realist process. Realism $i s$ illusory [...] in an almost postmodern way, they [...] create their worlds while being intensely and often explicitly self-conscious about the medium through which they are doing it, and worrying" (Levine, 2007, p. 16-19).

${ }^{9}$ Con este presupuesto, Villanueva propone su teoría sobre el realismo en base a la recepción. La ficcionalidad de los textos, afirma el autor (2004, p. 92-160), depende del lector que así los comprenda, tal como el realismo depende de la lectura intencionadamente realista del receptor, quien, de este modo, proyecta una visión de mundo externo sobre un mundo intensional que el texto sugiere.

${ }^{10}$ El ‘tipo' lukacsiano, por ejemplo; o el milieu de Aurbach; o la particularización de Ian Watt.
} 
convenciones) y a la ideología dominante ${ }^{11}$. Situado en este panorama general de renovación del realismo, Luiz Ruffato representa un caso sumamente explícito, arriesgado y estéticamente muy interesante, en su búsqueda de formas narrativas que expresen de algún modo la experiencia de realidad actual, con un compromiso altamente político, pero también estético. Si la literatura es capaz de representar la realidad es también capaz, dentro de sus propios límites, de producir cambios en ella.

\section{El ‘otro' realismo de Ruffato}

Situado en el centro mismo de esta tendencia actual, una de las mayores satisfacciones de la lectura de Luiz Ruffato es que nunca cesa de experimentar, de buscar, de trasgredir los límites trazados por su narrativa precedente. Incluso cuando en estas apuestas pareciera haber simplificado su narrativa, tan demandante en su primera novela y en Inferno provisório. Ha apostado en sus últimas novelas por textos más 'legibles', sin ostentación técnica, con relatos sencillos y oralizados ${ }^{12}$. Sin embargo, esta aparente simplicidad supone una nueva línea de evolución en su proyecto narrativo, que continúa indagando en las posibilidades de representación y de realidad que ofrece la novela actual. Tanto en De mim já nem se lembra (2007, reeditada y ampliada en 2016), Estive em Lisboa e lembrei de você (2009) y particularmente en Flores artificiais (2014), el autor asegura simplemente transcribir y eventualmente editar estilísticamente relatos que no le pertenecen (cartas, una entrevista y un diario), de sujetos reales y absolutamente comunes. Estos textos 'reales' no dejan de ser, sin embargo, narraciones íntimamente literarias del autor; son historias mínimas que -por lo mismo- se vuelven profundamente humanas, y vienen a evidenciar una vez más una demanda de realidad en las literaturas actuales.

Este 'giro' evidencia diversos aspectos. Por un lado, un aparente agotamiento de las formas de irrupción experimental: el experimentalismo, una vez asentado, crea una expectativa lectora en que todo efecto buscado por la novedad (la 'forma obstruyente', citando a Shklovski) al normalizarse se pierde; por otro, un desplazamiento de los aspectos de realidad que se busca representar, tensionar o desmitificar. Se trata, en los tres textos aquí tratados, de volver a historias más simples y humanas, en la más general de sus acepciones. Textos que el autor minero graba, descubre o recibe, y luego edita y publica en forma de novela. Son, sin lugar a dudas, historias sin (entre gruesas comillas) ningún interés, puesto que los que hablan no son personajes históricos destacados, ni víctimas ni testigos de la revolución o la masacre. Son personajes comunes y corrientes. Curiosamente, y esa es una de las propuestas acá, eso las convierte precisamente en historias más profundas y conmovedoras en sus guiños a la realidad sin trascendencia. Son, como veremos hacia el final de este artículo, vías estéticas de rearticular a un sujeto desmembrado y descentrado y su subjetividad a través de una subjetividad otra ${ }^{13}$.

\section{Elegía al hermano muerto}

De mim já nem se lembra fue publicada en 2007, como texto infanto-juvenil (que no tuvo mucho éxito) pero su versión revisada, ampliada y definitiva es de 2016. En su "Explicação necessária" (p. 11-22) el autor presenta el texto como la recopilación y edición de las cartas que su hermano mayor, José Célio, mandó a su madre entre 1971, cuando emigra a São Paulo "en busca de oportunidades", hasta 1978, cuando muere en un accidente camino a su hogar en

\footnotetext{
${ }^{11}$ A propósito de los nuevos realismos, señala uno de sus principales estudiosos: "O escritor contemporâneo parece estar motivado por uma grande urgência em se relacionar com a realidade histórica, estando consciente, entretanto, da impossibilidade de capta-la na sua especificidade atual, em seu presente [...] passando a aceitar que sua 'realidade' mais real só poderá ser refletida na margem e nunca enxergada de frente ou capturada diretamente. Daí perceberam na literatura um caminho para se relacionar e interagir com o mundo nessa temporalidade de difícil captura" (Schøllhammer 2009, p. 10-11).

${ }^{12}$ Este artículo fue escrito antes de la publicación de $O$ verão tardio (2019).

${ }^{13}$ No soy un lector tan ingenuo como para presuponer la existencia efectiva de todos estos documentos. Pero es un juego literario, de la más alta trascendencia, que se nos invita a seguir. Y en este artículo así se hará. No se trata de autenticar dichos relatos, sino de la experiencia estética de la novela y sus posibles lecturas y efectos.
} 
Cataguases. "Luizinho" aparece como un personaje secundario en el trasfondo de las cartas, y la voz de Luiz se oye en el mencionado prólogo, en algunas notas al pie, ${ }^{14}$ y en un emotivo epílogo, presentado como una carta a su fallecido hermano. En la nota final del prólogo indica: "As cartas reproduzo-as integralmente, apenas atualizando e corrigindo a ortografia e muito raramente a pontuação - procurei manter sua quase oralidade" (p. 22). Lo que motiva este texto, por lo tanto, es un hecho real. Sin embargo, el autor publica este y los otros objetos de los que hablaré como novelas, situando el estatuto óntico de la narración en la ficción. Puede que las cartas no sean auténticas, pero cargan con un peso gigante de verdad, en una ficcionalidad muy cerca de romper sus propios límites.

La novela, por ende, no se agota en su referencialidad ni mucho menos. En tanto texto literario supone si no necesariamente clausurar, sí al menos poner entre paréntesis las condiciones de verdad. En tanto efecto, se acerca a lo que Schøllhammer llama realismo indicial, donde se trata de traer la presencia de lo real al texto, aunque sea en un nivel simbólico, trayendo al texto literario abundantes marcas indiciales, signos que lo que muestran "não está fora deles mesmos, apenas referem-se a sua própria existência [...] fotos que não servem apenas para ilustrar o texto, mas, ao contrário, criam uma tensão que corrói os recursos narrativos convencionais e a relação equilibrada entre a história e a imagem" (2012a, p. 141). En este caso el índice, se supone, es el texto (las cartas), y lo que le da orden y sentido a estas cartas son el prólogo y el apéndice, nuevamente en voz del autor real, no de un narrador (aunque esto también es, por supuesto, un efecto pretendido).

Pensemos ahora, pues, el texto como novela, con la clara sospecha de que las cartas sean ficcionales (digamos, su escritura efectiva). ¿Cómo se integra este texto dentro del proyecto escritural, e incluso ético-político del autor? Cabe señalar, por una parte, que la novela se puede leer como una mirada íntima (ya que es un relato epistolar y personal y afectivo) del proceso de migración y luego asentamiento obrero de las grandes ciudades, que es uno de los temas más relevantes en la narrativa del autor. La novela, así, dialoga profundamente con Inferno Provisório, donde José Célio podría perfectamente ser personaje: la llegada del migrante ("Nunca tinha viajado tanto tempo dentro de um ônibus [...] A rodoviária é muito bonita. Grande que só vendo [...], pp. 25-26); el incierto futuro y la saudade ("... e me deu uma coisa na garganta, medo de nunca mais voltar a ver a senhora, o pai, o Luizinho, a Lúcia, os meus amigos, a nossa casa", p. 26); el deseo y la imposibilidad del regreso ("a sensação que fica é que nunca mais vou voltar. Isso é muito triste, porque aqui não é o meu lugar. Mas sinto que aí já não é o meu lugar", p. 89), etc. ${ }^{15}$

Por otra parte, en esta novela se presenta un trasfondo político mucho más explícito que en sus textos anteriores (profundamente políticos, pero no necesariamente por su representación histórica). El movimiento obrero y sus peligros, las desapariciones, las huelgas y la represión, se mencionan constantemente en las cartas de Célio contando su vida en São Paulo. Nos muestra la reorganización obrera en el panorama del liberalismo y globalización económica al alero de la dictadura y el 'milagro económico', a través del proceso de adaptación y paulatina politización del narrador; significativamente, la penúltima carta, de febrero de 1978 anuncia: "o negócio aqui está pegando fogo. O nosso primeiro de Maio vai ser uma demonstração de forca da categoria" (p. 126), anunciando las huelgas generales de mayo del 78, que significaron la reorganización obrera tras el AI-5, el surgimiento de Lula como líder obrero, y por lo tanto, marcando todo el proceso social pero fundamentalmente político, que culminó en los gobiernos del PT.

La novela, así, tensiona fuertemente los límites de lo ficcional y lo real. Aun sabiendo que las cartas no fueron escritas por su fallecido hermano, el compromiso afectivo es tan real como las

\footnotetext{
${ }^{14}$ Las notas dan alguna información contextual básica (a cuánto equivale hoy el sueldo que ganaba, contexto histórico, etc.), lo que 'autentica' las cartas, y le da voz al autor como comento. Por ejemplo, esta nota de la carta del 1 de mayo de 1973 (p. 67): "É provável que uma carta, anterior a essa tenha se extraviado ou perdido, porque não há maiores comentários a respeito da família da Nena à nossa casa...". Como 'relato encontrado' es, por defecto, incompleto.

${ }^{15}$ Como señala el autor en el epílogo, “dividíamo-nos, por essa época, em 'os que já haviam ido embora' e 'os que ainda não tinham idade para isso'..." (p. 134). Esta misma experiencia es la que podemos ver, por ejemplo, en la historia de Luzimar con que comienza el volumen II de Inferno, $O$ mundo inimigo, y que se va complementando en distintos momentos a lo largo de la novela.
} 
cartas que 'podría haber escrito' su hermano. El epílogo, de 2008, es una emotiva carta que termina con un "envelheci, envelhecemos todos... Menos você, que permanece com 26 anos, ardendo inexoravelmente em minhas lembranças" (p. 136), cuyo dolor no puede ser cuestionado en su autenticidad. Política de los afectos.

Los procesos de industrialización y urbanización acelerados desde el Estado Novo en adelante, pero sobre todo la violencia en dictadura, trajo como consecuencia la emergencia de nuevos sujetos colectivos, y consecuentemente, una "reorganización de la economía de afectos" (cfr. López y Nitschack, 2018, especialmente p. 111 y 113; Brasil se abre a la fase del capitalismo avanzado, es decir, la postmodernidad). Lo que podemos llamar la fragmentación del sujeto contemporáneo -tan bien configurado en eles eram- y una nueva forma de violencia en la 'neo-favela' tienen que ver precisamente con esta tensión entre modelos tradicionales y su supresión en sociedades actuales. Esta novela, pienso, quiere ir un paso más allá, buscando reconstituir la imagen de este sujeto escindido y su (imposible) unicidad, a partir del ejercicio estético (por ende, político) de la recuperación de una subjetividad otra a la cual, sin embargo (así lo dice el prólogo y el apéndice), ya es imposible llegar. Y es entonces, tal vez, el mismo Ruffato el que busca constituirse como sujeto a través de una subjetividad que no es la suya, indicando el camino (afectivo) que nosotros lectores podemos seguir, en este ejercicio que es tan estético como político.

\section{La banalidad del mundo}

Formalmente, Estive em Lisboa e lembrei de vocêê se asemeja a la novela anterior en que también asegura ser la transcripción de un relato real, "un testimonio, mínimamente editado, de Sérgio de Souza Sampaio, nacido en Cataguases (Minas Gerais) el 7 de agosto de 1969, grabado en cuatro sesiones, durante las tardes de sábado de los días 9, 16, 23 y 30 de julio de 2005" (p. 13). Se lee como novela (ficción), pero sabemos (o jugamos a saber) que es un testimonio, en primera persona, de un personaje real. De modo que en esta no existen ninguna de las exquisiteces técnicas y estilísticas que tenían sus novelas más conocidas. Se trata aquí de acercarnos lo más posible a la voz (real) de una persona común, en la que el novelista solo opera como un editor y como un corrector estilístico, lo que, paradojalmente, es lo que le da el valor artístico a este relato; algo así como el objet trouvé de los surrealistas, solo que lo 'encontrado' aquí es una historia personal.

Frente al tradicional testimonio, tal como el anterior, este texto se presenta paradojalmente como como un relato de ficción, cuyo referente es el discurso oral de una persona real. Pero, además, se trata de un personaje que, en términos generales, no tiene ningún interés particular. No se trata de un oprimido, de un marginal, de un revolucionario, sino de una persona común y corriente, pueblerino, de una clase media baja, que cuenta su historia, el cómo llegó a Lisboa y por qué, una historia como la de cualquier otro y que no concluye en nada, en tanto es una historia (una vida) en curso. ${ }^{17} \mathrm{Y}$ aquí es donde se nota la mano del autor y su proyecto escritural, puesto que estamos frente a una de esas tantas 'historias mínimas' de sus primeras novelas pero ahora desde un foco inverso, no desde la fragmentariedad sino desde la extensión. Se nos relata una historia sin trascendencia, pero es justo en ese minimalismo que la historia nos acerca experiencialmente: una historia sencillamente cotidiana que aún no encuentra un cierre.

No podemos saber realmente cuánto es de Ruffato y cuánto del discurso original (si es que lo hubiere), pero eso está en la intencionalidad misma de la novela y no deja de ser un artefacto, en el buen sentido: una artesanía de lenguaje. El manejo poético de la lengua se evidencia de

\footnotetext{
${ }^{16}$ A diferencia de los otros textos, citados en su idioma original, para Estive em Lisboa... utilizo la traducción de Mario Cámara, para Eterna Cadencia, debido a un simple problema técnico: no tengo el original en portugués en mi poder -la importación de libros desde Brasil es un gran problema, acá en Chile. Prefiero, pues, mantener las citas de los textos publicados de los que dispongo.

${ }^{17}$ Este es, de hecho, uno de los problemas más tradicionales del realismo: "Realist writers have struggled since with the difficulty of reconciling the wish to represent the real-life dullness of nothing much ever happening 'out of the ordinary' with the need to maintain some sort of narrative interest (or readerly awakeness)" (Bowlby, 2007, p. xiv). Aquí el ejemplo más notable es, por supuesto, Madame Bovary. Solo que en Estive em Lisboa ni siquiera hay una tragedia que enmarque lo banal. Estas historias mínimas serían el paso lógico que sigue a esta representación de personajes comunes: son personajes 'como nosotros', viviendo historias 'sin importancia' (como las nuestras).
} 
manera sutil, en la medida en que la narración de Estive es profundamente oralizada, casi se oye a Serginho hablar, marcada por un ritmo prosódico perfectamente trabajado, que al menos nos permite entrar en la ilusión de que efectivamente se trata de un relato 'mínimamente editado' por el autor y accedemos casi directamente al habla del personaje: las derivaciones de un tema a otro, las repeticiones, los énfasis típicamente orales, las frases incompletas, las ideas sueltas. Pero ese divagar del lenguaje se convierte en un relato envolvente, repito, por lo enternecedor y humano. La novela está llena de humor, de ternura, de exageraciones y una autoironía muy woodyallenescas. Así, por ejemplo, hablando al azar de sus mujeres describe lo que sería su fallido matrimonio:

Por desgracia se embarazó justo Noemí, de la cuadra, vecina nuestra, de mala fama en el barrio, que simpatizó conmigo cuando conseguí cambiar el scooter por una 125 retirada nuevita de la concesionaria, hija de Ponté Carvalho, caboclo a la antigua, rústico y metódico, que entró en el comedor armado con un trabuco, profiriendo que habría matrimonio, "¡Aunque sea en la comisaría!", contra la opinión generalizada que dudaba de la paternidad, asustando a mi madre que, celosa de decoros y honra [...], empeñó su palabra en la combinación de la fecha [...] Resulta que se consagró una melancólica unión desde la raíz, festejo desproporcionado en el Club Aexas para no sé cuántas cabezas, por cuenta de los Carvalho, gente de comer radicheta y eructar pernil, multitud reclamante, la cerveza y el guaraná, calientes; los brochetes de carne, resecos; la mayonesa, cortada; la música, alta (para los viejos), bailantera (para los jóvenes); los dulces de coco, la torta, arrasados [...]; el lugar, apartado; la novia, desagradable (según el parecer de los míos); el novio, otario (al juicio de todos)" (p. 25-26; las cursivas son del original, y muestran el intento por de mantener los énfasis orales).

Pienso que esa perfecta oralidad (que irá progresivamente influenciándose del portugués de Portugal) es más que nada un efecto artístico de la novela. La cualidad oral, en este sentido, actúa como un índice, en el sentido en que es utilizado por Schøllhammer: el discurso oralizado, puesto en el contexto de una novela debidamente editada y publicada, no es más que un constructo que pretende traer 'lo real' a presencia por la relación de continuidad del índice peirciano.

Una de las marcas determinantes del realismo literario, como vimos al principio, no es tanto el representar 'las clases bajas' (la pequeña burguesía francesa dista mucho del proletariado escandalosamente incorporado por Zola, y Tolstoi se inclina en sus grandes novelas por la más rancia aristocracia), como se ha dicho en diversos lugares, sino la progresiva ampliación de los temas de representación 'serios' y la manera históricamente determinada de contarlos. ${ }^{18}$ Siguiendo esta línea, Cidade de Deus es característica de los nuevos realismos no por representar la marginalidad, sino por representar esta 'neo' marginalidad desde dentro (que se identifica, además, por una nueva codificación de los afectos), y por exigir transformaciones de las formas narrativas para dicha representación que escapa de los modelos clásicos. A partir de esta mirada histórica, me parece interesante este giro, en que la ampliación de estos objetos de representación no pasa por el rango social de los sujetos representados, sino por el tipo de personaje y sus historias. Lo interesante de Serginho (y, como veremos, de Dório) es que su historia es 'banal', es decir, como la de la mayoría de nosotros. El tratamiento, pues, se aleja de la tragedia, de los avatares de la historia con mayúscula. En Germinal, en O cortiço, la miseria se traducía en un espejo del sufrimiento humano, de las grandes injusticias del hombre. La historia de Serginho no tiene que ver con la miseria humana. De hecho, con todos sus avatares, le va bien; pero tampoco tanto. En ese sentido es una historia 'sin importancia', que se organiza en torno al fumar y dejar de fumar como grandes nudos del relato. ${ }^{19}$ Lo mágico de este discurso es que nos permite involucrarnos en un nivel más cercano y sensible, como con la historia de un

\footnotetext{
18 Auerbach sigue explícitamente esta línea, pero implícitamente también Hauser, y opinan lo mismo, entre otros, Beaumont, Bowlby, Levine, etc. La ampliación hacia las clases primero medias (la pequeña burguesía) y luego bajas forma parte de este proceso democratizador, pero ciertamente no es la única ampliación del repertorio representacional.

${ }^{19}$ La primera parte se llama "Cómo dejé de fumar" y la segunda "Cómo volví a fumar", contando su historia en una serie de divagaciones en torno a estos dos hitos: "Volví a fumar después de seis años y medio...” (p. 17, y luego va contando cómo logró dejarlo), abre el relato, que se cierra con un "pedí un paquete de cigarrillos SG, un encendedor, saqué un cigarrillo, lo encendí, y volví a fumar" (p. 92). Nada más banal, pues, puede enmarcar esta vida común.
} 
amigo o un pariente. Porque estas sí son historias 'como las nuestras'. La aventura 'heroica' (el provinciano humilde que viaja a la metrópoli a hacer fortuna, como muy humorística y literariamente le hacen sentir sus coterráneos) rápidamente se desinfla; y la posible tragedia (las desafortunadas aventuras de este extranjero en busca de oportunidades, la pérdida de trabajo, del pasaporte, etc.), trae como funesta consecuencia... el volver a fumar.

\section{La experiencia global}

La última novela de Ruffato, Flores artificiais, ahonda aún más en la relación entre texto y realidad. El autor se explica en la "Apresentação" (p. 9-11): luego de la publicación de De mim y Estive em Lisboa, recibió muchas cartas pidiendo que publicara su historia, lo que sistemáticamente rechazó. Pero una de ellas, escrita por un ingeniero jubilado y coterráneo suyo, Dório Finetto, le llama la atención, por su sinceridad. Simplemente, le hace entrega de los seis cuadernos que terapéuticamente escribió para salir de su depresión, contando parte de su vida, para que haga con ellos lo que quiera. ${ }^{20}$ Rufatto los lee, y aunque cree que hay bastante material, necesita claramente una edición, un 'pulido de estilo' ("expus meu diagnóstico assunto demandando estilo- e ele teimou que, então, 'envernizasse a trama' segundo meus predicados", p. 10). La selección, orden y edición estilística corren por parte de Ruffato en la novela que nos entrega, tan real como (así dice su título) artificial, como las flores plásticas que se ven perfectamente naturales mientras uno mantenga una cierta distancia, pero que basta una mirada cercana para descubrir su materialidad -su artificio. El autor tiende todos los puentes necesarios para esta imbricación, y le queda al lector el entramado; incluye el mencionado prólogo, la carta original que Finetto le mandara y, al final, un breve esquema biográfico narrado en estilo ruffatiano, en el que, sin embargo, Dório "afirma não se reconhecer. Se pilhéria do biografado ou incompetência do retratista, eis a questão" (p. 11). Esa misma 'cuestión' es la que le deja al lector, en este juego entre afectos y efectos (narrativos), entre ficción y verdad -o verdad de las ficciones. ${ }^{21}$

Otra vez se pone en valor el habla perdida del 'hombre sin atributos'. Pero, a su vez, incorporando todos los índices de realidad en paralelo con las marcas de ficcionalidad. Así, la novela es tan 'flor' como 'artificio', es tan constructo poético como testimonio real (el autor quería incluir a Finetto como co-autor de la novela, cosa que este rechazó tajantemente). ${ }^{22}$ Significativamente, el primer relato se titula "Uma história inverossímil" (p. 21-46), cuestionando de entrada la credibilidad de lo que se supone real en esta ficción. Así se justifica esta historia (que reconstruye la historia de otro personaje, Bobby Clarke): “Este é um arremedo de biografia, construída como pontes pênseis sobre abismos. Tudo que sei sobre Bobby, lembranças de lembranças, foi-me relatado de maneira caótica, com largos lapsos e imensas contradições. E costuro esses fragmentos, ouvidos há mais de trinta anos, com uma linha que já não distingue memória e imaginação" (p. 24). Recuerdos sobre recuerdos, para construir una historia que ya no distingue memoria (realidad) e imaginación (ficción). Una vida, parece decir esta historia, no es sino la superposición de múltiples relatos, versiones, recuerdos, discursos que van construyendo lo que entendemos por realidad, fundada sobre una serie de incertezas. ${ }^{23}$ De este modo, la novela se vuelve un relato que justifica una vida, una forma de hacerse

\footnotetext{
20 “O que tinha feito da vida? Não casei, não tive filhos, nunca mais tinha falado com meu irmão e nem com minhas irmãs. Não tinha amigos para conversar comigo [...]. Parecia que naquela sala vazia estavam todos meus fantasmas (p. 12-13).

${ }^{21}$ Esta pretendida "no originalidad" no es la única tensión con el modelo novelesco tradicional. También esta "novela" se conforma de una serie de "relatos" inconexos del mentado Dório (en los que él sistemáticamente no es el "protagonista", es siempre la historia de otro); la única organicidad de la novela estaría dada por la experiencia de este narrador/autor fantasma, lo que explica, además, la relevancia de los paratextos de Ruffato que componen y dan sentido a este texto.

${ }^{22}$ El artificio aparece, también, por sus referencias literarias: el título es -supongo- una composición entre dos libros de Baudelaire, las Flores del mal y los Paraísos artificiales.

${ }^{23}$ Esta disposición discursiva me recuerda la estructura de los relatos de Bernardo Carvalho, a quien también me inclino por incluir entre los realismos actuales. Esta búsqueda de una verdad posible a partir de relatos (o fragmentos) que se cruzan, contradicen, complementan o superponen, y que sirven de metáfora a nuestra propia experiencia, es lo que se puede ver de manera más significativa especialmente en Nove noites y Mongólia.
} 
presente, de re-construirse y re-conocerse como sujeto, en sucesivas capas discursivas y existenciales (la experiencia, el relato de la experiencia, la escritura personal y la novelización). La técnica narrativa del seudodiegético descrita por Genette a propósito de Proust, ${ }^{24}$ adquiere aquí niveles complejísimos, que nos llevan a pensar nuevamente en los niveles de ficcionalización que aquí operan: las diversas voces que arman los fragmentos de la historia de Boby Clarke se funden, sin ninguna pretensión de 'verdad', seudodiegéticamente, en la pretendida- voz de Finetto, que a su vez habla solo desde la reproducción de Ruffato (quien al seleccionar y corregir estilísticamente los textos, los hace suyos, seudodiégesis de por medio). De este modo, ¿cómo podemos afirmar de quién es la voz en la novela, quién habla, y en qué nivel se encuentra la 'verdad' del texto?

Otra de las historias contenidas en la novela (que es, recuérdese, un compendio de historias escritas por Finetto y narradas por Ruffato, en esta cadena de artificios), la más larga de ellas, "El Gordo" (p. 58-88) opera de manera similar. El personaje del título es el central en esta anécdota que transcurre en un Uruguay popular, en torno al fútbol, el asado y el mate. En algún momento la conversación deriva en el relato de la desaparición del padre del Gordo durante la dictadura y su infructuosa búsqueda que termina en São Paulo. La historia que todos conocen. Pero hacia el final del relato el Gordo toma la palabra: “É que... talvez... eu preciso... acho... eu preciso... dizer uma coisa... A história... a história que contei sobre meu pai... que dizer... essa história que eu conto [...] não aconteceu bem assim..." (p. 77). ${ }^{25}$ De ahí comienza el relato "verdadero" de este papá que nunca fue detenido en dictadura, sino que se fugó a São Paulo con su otra familia, a la que, de paso, ya había abandonado en el momento en que el Gordo dio con su paradero, y logra conversar con la nueva exmujer; sin embargo "o diálogo que se estabeleceu a partir daí é, para mim, até hoje, confuso, incerto, irreal" (p. 83). La "verdad" que se inventa tiene un fundamento simple: "Meu pai... Ele... ele era... é... se estiver vivo... não sei... um grande... pelotudo de mierda" (p. 77). Veamos, pues, bajo cuántas capas queda el "acto verdadero" (o la posibilidad de construir verdades en la ficción): la historia de este padre (¿oculto bajo cuántas máscaras?) es contada desde la mirada rencorosa de la mujer en Brasil (a través de un diálogo "incierto, irreal"), según lo que cuenta el Gordo a Dório, en lo que Dório escribe y finalmente Ruffato ficcionaliza y narra, y cuya verdad última, en la vida del Gordo, sería la ficción que este se inventa (para sí y para todos).

Siguiendo el argumento que estoy trazando acá, la novela continúa el nuevo giro realista de las novelas anteriores, con una escritura cada vez más legible. Sin embargo, discursivamente, y a propósito de los lugares de enunciación, probablemente esta sea la novela más compleja de Ruffato, aunque no lo aparente. El narrador literario, que se distingue radicalmente (digamos, ontológicamente) de su autor, ha recibido diferentes caracterizaciones que iluminan esta diferencia, y que podemos concretizar en la figura del hablante imaginario. ${ }^{26}$ En el discurso dramático (me refiero a la versión textual del drama), en cambio, se distingue entre un discurso ficcional o imaginario, enunciado por los personajes y un discurso real, dirigido a receptores reales (quienes montan la obra), que es el discurso acotacional, que se traduce en los elementos no verbales en la representación escénica. ${ }^{27}$ Por otra parte, el prólogo a una novela es un género tradicional, que normalmente también asociamos al discurso del autor real (cercano, pues, al género de la memoria, la carta o el testimonio; donde, como señala Leonidas Morales, "al revés

\footnotetext{
${ }^{24}$ El recurso retórico que consiste en omitir un nivel diegético, manteniendo el narrador primero la voz en un relato que evidentemente no es suyo ("consiste en contar como diegético, en el mismo nivel narrativo que el contexto, lo que, sin embargo, hemos presentado (o se deja adivinar fácilmente) como metadiegético en su principio"). Ver Genette (1989, p. 283-298, especialmente p. 290-291).

${ }^{25}$ La necesidad de decir como un ajuste de cuentas con uno mismo (un decir como existir) es claramente un leitmotiv de la novela. Contar la historia de otros para construir una autoafirmación identitaria.

${ }^{26}$ Ver Martínez (1960, p. 43-66, y especialmente p. 97-102).

27 "La obra dramática, en tanto texto, está constituida por dos tipos de lenguaje que funcionan de modo diverso, y que solo uno de ellos -el que reproduce el discurso dramático- es autosuficiente como lenguaje"; estos dos niveles discursivos son el discurso dramático "imaginario" de los personajes, y el discurso acotacional, que opera como una "semia sustitutiva" -un sistema significante indirecto, que sustituye semias directas no lingüísticas por imposibilidad del texto lingüístico de reproducirlas directamente (Vaisman 1979, p. 16 y 14)
} 
de lo que ocurre en los [discursos] ficcionales como la novela, autor y sujeto de la enunciación (o 'narrador') coinciden: son el mismo", 2001, p. 11). Sin embargo, lo que convierte a esta novela en novela es precisamente la presentación. De este modo, si bien podríamos distinguir esa dualidad en la novela, es evidente que explicación y texto forman un todo discursivo: no hay novela sin prólogo y viceversa. ${ }^{28}$ Esta homogenización discursiva achata o comprime nuevamente los límites entre ficción y verdad, incorporando la presentación del autor que suponemos real dentro de la ficción narrativa y la 'verdad' del texto se traslada hacia el ámbito de la construcción discursiva.

Cabe decir, por lo demás, que en esta novela se abre definitivamente el proyecto ruffatiano al problema de la experiencia global (y la soledad y 'nueva alienación' propias de esta globalización). La fijación por una narrativa local en sus primeras novelas es perfectamente comprensible: escribe desde su propia experiencia, su lugar en el mundo (el ciclo de la classe operária de Inferno, desde la inmigración italiana a la emigración hacia São Paulo, y la experiencia cotidiana de dicha megalópolis, en eles eram, son experiencias efectivamente vividas por el autor). Pero bien, la economía actual y la sociedad contemporánea se definen por la experiencia global: el 'aquí y ahora' es en todas partes, desde el mercado a la hipertrofiada informática. En Flores (que narra las experiencias de este solitario ingeniero por el mundo) pareciera aceptar, pues, esta nueva arista del ser-en-el-mundo de hoy, consecuente con su proyecto.

Las novelas aquí comentadas abren otra dimensión de esta búsqueda, volviendo hacia formas simples y legibles, puesto que su fuerza estética no radica en el estilo composicional, sino en el peso de 'verdad' o autenticidad del relato, con personajes que no se 'parecen' a los de la vida real, sino que están extraídos directamente de ella. O quizás no. Como dice Schøllhammer (2016, s.p.): "Falas e escritos de personagens que não são mais representados literariamente, mas apropriados e incluídos em sua própria materialidade", y, apunta, además, que no interesa mucho discutir si ese juego es real o ficcional. Y es en esa tensión, donde la ficción no pierde fuerza en su vectorización hacia la realidad, donde radica el potencial estético de estos textos, que son profundamente verdaderos en su ficción, radicalmente literarios en su elaboración discursiva de 'verdades', y de manera sumamente consciente. Pero las novelas no se agotan en su simpleza o su 'verdad'. Como textos literarios son (ocultamente) complejos, hiper-conscientes de su medio y su materialidad, con artificios discursivos como los recién explicados, y llenos de juegos intra y metatextuales que las densifican semánticamente, a la vez que hacen ostensible su literalidad. Uno de ellos, casi anecdótico, era el señalado por el título de Flores artificiáis. Pero, como ejemplo, el más interesante y complejo, es el de "O Beco do Zé Pinto", que es el lugar donde se concentran las historias cataguasenses del ciclo de Inferno, diversas historias aisladas que de alguna manera convergen allí; el claro modelo de éste, una referencia y homenaje a uno de los modelos literarios declarados por el autor, es el cortiço en la homónima novela de Aluísio. Sin embargo, en De mim já nem se lembra, aparece mencionado en las cartas de José Célio, nuevamente, "O Beco do Zé Pinto" como lugar de encuentro, convirtiéndolo, entonces, tanto en una construcción ficcional como en un intertexto literario, a la vez que en un referente real. La novela, así, dialoga tanto con el referente histórico como con su propia literatura, en un juego metatextual que viene a autenticar, a posteriori, la 'verdad de la ficción' de Inferno, con varios intertextos en juego.

\section{Conclusiones}

Tal vez una de las características centrales de la teoría sobre la posmodernidad en tanto condición material y económica con repercusiones necesarias en lo social, político y estético, es la concepción de un sujeto escindido, fragmentado o diferido (Derrida), ${ }^{29}$ que ha perdido sus

\footnotetext{
${ }^{28}$ Se podría pensar acá en la inversión entre centro y margen como estrategia de lectura propuesta por Derrida, pero desde la escritura ruffatiana.

${ }^{29}$ En el sentido derrideano del sujeto como un efecto del lenguaje, una escritura perpetua gobernada por la differánce, que, en su diferir, impide la consolidación de un sujeto (en tanto subjetividad) coherente, unitario y permanente.
} 
determinaciones y que ya no puede concebirse como unitario ni construirse a sí mismo en tanto identidad, con una subjetividad en crisis, ${ }^{30}$ lo que se traduce, estéticamente, en "a expressão literária de uma individualidade desprovida de conteúdo psicológico, sem profundidade e sem projeto" (Schøllhammer, 2009, p. 31); esto trae como consecuencia, a su vez, "no sólo una liberación de la angustia sino también de todo tipo de sentimiento, al no estar ya presente un yo que siente. [...] No obstante, el ocaso del afecto también se puede identificar [...] con el declive de las grandes temáticas modernistas del tiempo y la temporalidad, de los misterios elegiacos de la durée y la memoria" (Jameson, 2001, p. 33). El sujeto enajenado de principios del XX muta al sujeto fragmentado y deconstruido de finales del mismo siglo; la pérdida de las certezas que sustentaban la ideología moderna, han transformado a este sujeto supuestamente en plenitud de sus libertades en un sujeto atrapado en su propia falta de identidad, en su desmembramiento y anomia. ${ }^{31}$

La imposibilidad referencial que ha marcado la crisis de la representación se sustenta fundamentalmente, a mi juicio, en esta visión en extremo subjetiva de la realidad: solo hay sujetos que perciben, ninguna sustancia detrás de sus percepciones. Pero creo que el cuestionamiento va más allá: ya no hay sujetos que perciben, puesto que la misma noción de sujeto está en tela de juicio y cualquier intento por representar una realidad estable se siente como una imposición, un discurso ideológicamente concebido para dominar al resto, creando una falsas estabilidades y unidades donde no la hay, ejerciendo, de paso, una violencia sobre las otras subjetividades.

Esta posición del sujeto explica buena parte de las búsquedas de los realismos actuales: las capas sucesivas de 'verdad' y el giro inverosímil en Carvalho (o en Aira), la desterritorialización, la pérdida identitaria y acronía en Noll, etc. Estas novelas de Ruffato no enmascaran su propensión a rescatar, de algún modo, esa subjetividad perdida, que es, a su vez, una forma de autenticarse como sujeto (aun cuando 'no se puede'). ${ }^{32}$ El sujeto se incorpora críticamente al discurso, nuevamente, como una posibilidad, como una búsqueda constructiva, ficcionalizándolo (se hace ficción del sujeto en tanto que sujeto que percibe o que intenta integrar su identidad).

Es precisamente en estos sentidos en que estos textos se asumen como respuesta -como una modalidad del realismo- a su tiempo. En las tres novelas Ruffato pareciera borrarse (voluntariamente) como sujeto, como autor en tanto hablante: asume el discurso de otros. En su propia imposibilidad de autodeterminarse como un ego que enuncia, Ruffato da voz -como ego- a sujetos que se constituyen como posible subjetividad en tanto discurso (literario). En conclusión, si el sujeto es aquel que se manifiesta en el lenguaje y por el lenguaje, y, por otra parte, el sujeto moderno ha perdido su centralidad, estas novelas, en su aparente simpleza, me parecen ejercicios radicales de la (posibilidad de) reconstitución de una subjetividad: un sujeto que en el habla es capaz de afirmarse y trascender las experiencias vividas. A través de un desplazamiento para nada inocente, Ruffato ejercita la posibilidad de (re)constituir una subjetividad perdida (¿la suya, la nuestra?) a partir de otro que habla en la voz vaciada del autor; un ego que no logra constituirse y que a cambio presta su voz y usa la voz de otros como atestación de realidad.

\footnotetext{
${ }^{30}$ Señala Jameson que "desde numerosas y diferentes perspectivas, los teóricos sociales, los psicoanalistas y hasta los lingüistas, para no mencionar a quienes trabajan en el área de la cultura y el cambio cultural y formal, exploran la idea de que este tipo de individualismo e identidad personal es una cosa del pasado; que el viejo individuo o sujeto individualista está 'muerto'; y que incluso podrían describirse como ideológicos el concepto del individuo único y la base teórica del individualismo" (2002, pp. 20-1); se trata, pues, de "la muerte del sujeto como tal —esto es, el fin de la mónada, del ego o del individuo burgués autónomo" (2001, p.32). Lipovetsky, por su parte, caracteriza al 'yo' de la época postmoderna como vaciado de identidad, "el Yo pierde sus referencias, su unidad, por exceso de atención: el Yo se ha convertido en un 'conjunto impreciso'. En todas partes se produce la desaparición de la realidad rígida, es la desubstancialización, última forma de extrapolación, lo que dirige la posmodernidad” (2002, p. 56).

31 "La erosión de las referencias del Yo es la réplica exacta de la disolución que conocen hoy las identidades y papeles sociales, antaño estrictamente definidos, integrados en las oposiciones reglamentadas: así el estatuto de la mujer, del hombre, del niño, del loco, del civilizado, etc., han entrado en un período de indefinición, de incertidumbre, donde la interrogación sobre la naturaleza de las 'categorías' sociales no cesa de desarrollarse" (Lipovetsky, 2002, p. 59).

${ }^{32}$ Estoy recuperando aquí la idea de subjetividad como marca en el lenguaje, propuesta por Benveniste: "Es en y por el lenguaje como el hombre se constituye como sujeto; porque el solo lenguaje funda en realidad, en su realidad que es la del ser, el concepto de 'ego' [....]. La 'subjetividad' [...] es la capacidad del locutor de plantearse como 'sujeto' [, que a su vez se define] como la unidad psíquica que trasciende la totalidad de las experiencias vividas que retiene, y que asegura la permanencia de la conciencia” (2004, p.180).
} 
En un giro más radical aun, se podría decir que Flores hace ese desplazamiento de la voz que habla (del sujeto que se subjetiva en el discurso) una cadena metonímica: Dório, en estos cuadernos, no habla nunca de sí: su hacerse sujeto es contando al otro, dándole, sin saberlo, voz: la forma misma de la novela pareciera negar la posibilidad de la subjetividad, y sin embargo mi planteamiento es opuesto. Este ejercicio ostensivo de desplazar al yo (ficcional) que habla, es un camino alternativo, problemático y provocador de autoconstituirse como sujeto.

Ahora, si consideramos que todos los supuestos hablantes originales podrían ser una invención del autor real, editados por un autor implícito, pareciera desmantelar toda esta reflexión. A mi juicio, no. Sería un caso extremo de la ilusión indicial. Que nos preguntemos por la existencia de estos sujetos es determinante: al parecer, ahora volvemos a estar autorizados a preguntarnos por la 'verdad' de la literatura. Es en ese imposible encuentro intersubjetivo entre sujetos desplazados donde emerge lo real en el sentido que lo utiliza Hal Foster siguiendo a Lacan (1996).

En fin, si algo nos demuestran estas novelas es que es imposible reducir a estos nuevos realismos a una fórmula única, y que el autor minero seguirá explorando estas distintas posibilidades probablemente hasta su agotamiento. Esta demanda de realidad en un contexto en que las posibilidades de definir un principio único han desaparecido, y en que el modo realista tradicional se aleja cada vez más de una representación adecuada de la experiencia contemporánea, se hará patente en su constante búsqueda. La historia misma de los realismos demuestra que una vez que estas diversas propuestas se hayan asentado en un género o estilo más o menos homogéneo y transversalmente aceptado, se abrirán nuevas posibilidades críticas que aún no podemos prever. El realismo, debe recordarse, no se satisface con 'copiar' la realidad; el realismo es constructivo, no 'copia' verdades, las propone. Mi sugerencia final sobre la resistencia del sujeto en un contexto en que sus límites se han borrado, demuestra tanto la continuidad con el proyecto (y no la forma) del realismo clásico, como su propuesta ética y política.

\section{Referencias}

AUERBACH, Erich (2001). Mimesis: la representación de la realidad en la literatura occidental. México, D.F.: Fondo de Cultura Económica.

BEAUMONT, Matthew (2007). Introduction: Reclaiming Realism. In: BEAUMONT, Matthew (Ed.). Adventures in Realism. Oxford: Blackwell Publishing. p. 1-13.

BENVENISTE, Emile (2004). Problemas de lingüística general. v. I. México, D.F.: Siglo XXI.

BOWLBY, Rachel (2007). Foreward. In: BEAUMONT, Matthew (Ed.). Adventures in Realism. Oxford: Blackwell Publishing. p. xi-xviii.

FOSTER, Hal (2001). El retorno de lo real: la vanguardia a finales de siglo. Madrid: Akal.

GENETTE, Gérard (1989). Figuras III. Barcelona: Lumen.

JAMESON, Fredric (2001). Teoría de la posmodernidad. Madrid: Trotta.

JAMESON, Fredric (2002). El giro cultural. Buenos Aires: Manantial.

LEVINE, George (2007). "Literary realism reconsidered: 'The world in its length and breadth'". In: BEAUMONT, Matthew (Ed.). Adventures in Realism. Oxford: Blackwell Publishing. p. 13-32.

LIMA, Luiz Costa (2000). Mimesis: desafio ao pensamento. Rio de Janeiro: Civilização Brasileira.

LIPOVETSKY, Gilles (2002). La era del vacío. Barcelona: Anagrama.

LÓPEZ, Natalia; NITSCHACK, Horst (2018). Comunidad y afectos en la literatura marginal brasileña. Estudios Avanzados, n. 28, p. 108-120.

LUKÁCS, Georg (1965). Ensayos sobre el Realismo. Buenos Aires: Siglo XX.

LUKÁCS, Georg (1966). Problemas del Realismo. México: Fondo de Cultura Económica.

LYOTARD, Jean François (1987). La posmodernidad (explicada a los niños). Barcelona: Gedisa. 
LYOTARD, Jean François (2008). La condición postmoderna: informe sobre el saber. Madrid: Cátedra.

MARGATO, Izabel; GOMES, Renato Cordeiro (Org.). Novos realismos. Belo Horizonte: Editora UFMG.

MARTÍNEZ BONATI, Félix (1960). La estructura de la obra literaria. Santiago: Ediciones de la Universidad de Chile.

MORALES, Leonidas (2001). La escritura de al lado. Santiago: Cuarto Propio.

MORRIS, Pam (2003). Realism. New York: Routledge.

ROBBE-GRILLET, Alain (1965). Por una nueva novela. Barcelona: Seix Barral.

RUFFATO, Luiz (2005a). "Entrevista". Folha de S. Paulo, São Paulo, 19 mar. On-line. Disponível em: www1.folha.uol.com.br/fsp/ilustrad/fq1903200507.htm. Acesso em: 25 ago. 2019.

RUFFATO, Luiz (2005b). Mamma, son tanto felice (Inferno Provisório: Volume I). Rio de Janeiro: Record.

RUFFATO, Luiz (2005c). O mundo inimigo (Inferno Provisório: Volume II). Rio de Janeiro: Record.

RUFFATO, Luiz (2011). Estuve en Lisboa y me acordé de ti. Buenos Aires: Eterna Cadencia.

RUFFATO, Luiz (2012). Eles eram muitos cavalos. Rio de Janeiro: Record.

RUFFATO, Luiz (2014). Flores artificiais. São Paulo: Companhia das Letras.

RUFFATO, Luiz (2016). De mim já nem se lembra. São Paulo: Companhia das Letras.

SCHOLLHAMMER, Karl Erik (2009). Ficção brasileira contemporânea. Rio de Janeiro: Civilização Brasileira.

SCHOLLHAMMER, Karl Erik (2012a). Realismo afetivo: evocar realismo além da representação. Estudos de literatura brasileira contemporânea, Brasília, n. 39, p. 129-148.

SCHOLLHAMMER, Karl Erik (2012b). Do efeito ao afeto: os caminhos do realismo performático. In: MARGATO, Izabel; GOMES, Renato Cordeiro (Org.). Novos realismos. Belo Horizonte: Editora UFMG. p. 133-146.

SCHOLLHAMMER, Karl Erik (2016). Um mundo de papel: reflexões sobre o realismo de Luiz Ruffato. Alea: Estudos Neolatinos, v. 18, n. 2, p.232-242.

VAISMAN, Luis (1979). La obra dramática: un concepto operacional para su análisis e interpretación en el texto. Revista Chilena de Literatura, n. 14, p. 5-22.

VILLANUEVA, Darío (2004). Teorías del realismo literario. Madrid: Biblioteca Nueva.

WATT, Ian (1959). The rise of the novel: studies in Defoe, Richardson and Fielding. Berkeley; Los Angeles: University of California Press. 